\title{
BMJ Open Gender-specific prevalence and associated factors of hypertension among elderly Bangladeshi people: findings from a nationally representative cross-sectional survey
}

\author{
Abu Abdullah Mohammad Hanif (D) , ${ }^{1}$ Abu Ahmed Shamim, ${ }^{1}$ Md Mokbul Hossain, ${ }^{1}$ \\ Mehedi Hasan (D) , ${ }^{1}$ Md Showkat Ali Khan, ${ }^{1}$ Moyazzam Hossaine, ${ }^{1}$ \\ Mohammad Aman Ullah, ${ }^{2}$ Samir Kanti Sarker, ${ }^{2}$ S M Mustafizur Rahman, ${ }^{2}$ \\ Dipak K Mitra, ${ }^{3}$ Malay Kanti Mridha (D) ${ }^{1}$
}

To cite: Hanif AAM, Shamim AA, Hossain MM, et al. Gender-specific prevalence and associated factors of hypertension among elderly Bangladeshi people: findings from a nationally representative crosssectional survey. BMJ Open 2021;11:e038326. doi:10.1136/ bmjopen-2020-038326

- Prepublication history and supplemental material for this paper is available online. To view these files, please visit the journal online (http://dx.doi. org/10.1136/bmjopen-2020038326).

Received 06 March 2020 Revised 09 December 2020 Accepted 04 January 2021

Check for updates

(C) Author(s) (or their employer(s)) 2021. Re-use permitted under CC BY-NC. No commercial re-use. See rights and permissions. Published by BMJ.

For numbered affiliations see end of article.

Correspondence to Professor Malay Kanti Mridha; malay.mridha@bracu.ac.bd

\section{ABSTRACT}

Objective We aimed to estimate the gender-specific prevalence and associated factors of hypertension among elderly people in Bangladesh.

Design and method We analysed data from the food security and nutrition surveillance round 2018-2019. The multistage cluster sampling method was used to select the study population. Hypertension was defined as systolic blood pressure $\geq 140 \mathrm{~mm} \mathrm{Hg}$ and/or diastolic blood pressure $\geq 90 \mathrm{~mm} \mathrm{Hg}$ and/or having a history of hypertension. We carried out the descriptive analysis, bivariate and multivariable logistic regression to report the weighted prevalence of hypertension as well as crude and adjusted ORs with $95 \% \mathrm{Cl}$. A p value $<0.05$ was considered statistically significant.

Setting The study was conducted in 82 clusters (57 rural, 15 non-slum urban and 10 slums) in all eight administrative divisions of Bangladesh.

Participants A total of 2482 males and 2335 females aged $\geq 60$ years were included in this analysis.

Results The weighted prevalence of hypertension was $42 \%$ and $56 \%$ among males and females, respectively. The prevalence was higher among females across all sociodemographic, behavioural and clinical strata. Factors associated with higher odds of hypertension (adjusted OR $(\mathrm{AOR})(95 \% \mathrm{Cl})$ for males and females, respectively) were age $\geq 70$ years $(1.32(1.09,1.60)$ and $1.40(1.15,1.71))$; insufficient physical activity $(1.50(1.25,1.81)$ and 1.38 $(1.15,1.67))$; higher waist circumference $(2.76(2.22,3.43)$ and $2.20(1.82,2.67))$; and self-reported diabetes $(1.36$ $(1.02,1.82)$ and $1.82(1.35,2.45))$. Additionally, living in slums decreased $(0.71(0.52,0.96))$ and education $>10$ years increased odds of hypertension $(1.83(1.38,2.44))$ among males.

Conclusion In Bangladesh, half of the elderly persons were hypertensive, with a higher prevalence in females. In both sexes, odds of hypertension was higher among persons with older age ( $\geq 70$ years), insufficient physical activity, higher waist circumference and self-reported diabetes. The Ministry of Health of Bangladesh should
Strengths and limitations of this study

- Information on the prevalence, gender difference and associated factors of hypertension among the elderly Bangladeshi population are scarce.

- The nationally representative design allowed the objective assessment of the prevalence, gender difference and factors of hypertension among the elderly Bangladeshi population.

- Blood pressure was measured on a single day rather than longitudinal measurements to confirm the diagnosis of hypertension.

- The associations might not be causal due to lack of temporality, as the study was a cross-sectional one.

- Some strong confounders such as salt consumption and genetic factors could not be addressed.

consider these findings while designing and implementing health programmes for elderly population.

\section{INTRODUCTION}

The proportion of the ageing population around the world is rapidly increasing, and the pace is faster than ever. The global population aged $\geq 60$ years reached 962 million in 2017, more than double compared with that in 1980 and is projected to double again by 2050 when it reaches 2.1 billion. $^{1}$ In another estimate, globally, the population aged $\geq 60$ years will be $22 \%$ by the year 2050 , and $80 \%$ of them will live in low-income and middleincome countries. ${ }^{2}$ In 2017, $8.8 \%$ of the South Asian population was aged $\geq 60$ years, which is projected to be $18.9 \%$ by $2050 .{ }^{1}$ Despite the arbitrary nature of the cut-off age to define elderly population, individuals aged $\geq 65$ years are considered as elderly in most of the developed countries. ${ }^{3}$ However, 
in Bangladesh, individuals aged $\geq 60$ years are considered as elderly considering the shorter longevity. ${ }^{4}$ Bangladesh witnessed a fivefold increase in the elderly population between 1974 and 2001. ${ }^{5}$ According to the Bangladesh Bureau of Statistics, about 12.5 million $(7.5 \%)$ of Bangladeshi people were elderly in 2019, which is expected to be 40 million (20\%) by the year $2050 .^{6}$

Hypertension or raised blood pressure is a condition when the pressure of blood flow on the vessel walls become higher than normal. ${ }^{7}$ People often are not aware of whether they are hypertensive or not, and hence, it is often called the 'silent killer'. ${ }^{8}$ Globally, hypertension is one of the major causes of death and disability. According to the WHO Global Health Observatory 2016 data, 7.5 million annual deaths were estimated to be caused by high blood pressure, which was about $12.8 \%$ of total deaths worldwide. Hypertension is also accounted for 57 million disability-adjusted life years (DALYs), which amounts to $3.7 \%$ of total DALYs. ${ }^{9}$ Globally, hypertension is responsible for $45 \%$ of deaths from cardiac causes and $51 \%$ of the deaths from stroke. ${ }^{10}$ As a risk factor, hypertension causes nearly $30 \%$ of all cardiovascular diseases. ${ }^{11}$

The prevalence of hypertension substantially increases with age. Evidence from the Framingham Heart Study, the longest-standing study on cardiovascular disease epidemiology, showed that more than $90 \%$ of the normotensive (systolic blood pressure (SBP) $<120 \mathrm{~mm} \mathrm{Hg}$ and diastolic blood pressure (DBP) $<80 \mathrm{~mm} \mathrm{Hg}$ ) people at the age of 65 years would develop hypertension ( $\mathrm{SBP} \geq 140 \mathrm{~mm} \mathrm{Hg}$ and/or DBP $\geq 90 \mathrm{mmHg}$ ) due to age-related vascular changes during their remaining life span. ${ }^{12} \mathrm{Al}$ Kibria $e t$ $a l^{13}$ analysed the data from the Bangladesh Demographic and Health Survey 2011 (BDHS 2011) and reported that $30 \%$ of males and $52 \%$ of females aged $\geq 65$ years were hypertensive, along with $25 \%$ of both genders of the same age group were prehypertensive (SBP 120-139 mm Hg; DBP $80-89 \mathrm{~mm} \mathrm{Hg}){ }^{13}$ Another study reported that an estimated $23 \%$ of the elderly people in rural Bangladesh had undiagnosed hypertension (those who had no known hypertension but found hypertensive on measurement), and among those who were diagnosed and were receiving treatment, $68 \%$ had uncontrolled hypertension (blood pressure above the normal range despite antihypertensive treatment). ${ }^{14}$

Despite these facts, hypertension among elderly people in this region could not gain enough attention. One of the reasons can be limited information due to poor or no screening and control measures for hypertension among the elderly population. To the best of our knowledge, there is no study reporting national prevalence and factors associated with hypertension among the elderly Bangladeshi population. Accordingly, the objective of our study is to report the prevalence and factors associated with hypertension among elderly males and females of Bangladesh.
MATERIALS AND METHODS

\section{Study design and site}

We conducted a cross-sectional survey among six population groups (children $<5$ years, adolescent boys, adolescent girls, adult females, adult males and elderly people). Our objective was to generate nationally and divisionally representative estimates of different nutrition and healthrelated variables, including major non-communicable diseases (NCDs) in elderly males and females. The data collection period was from October 2018 to October 2019. In this nationally representative study, we enrolled participants from all eight administrative divisions (Barisal, Chattogram, Dhaka, Khulna, Mymensingh, Rajshahi, Rangpur and Sylhet). We covered rural, nonslum urban and slum areas. We enrolled study subjects from 82 randomly selected clusters ( 57 rural, 15 non-slum urban and 10 slums).

\section{Sample size and sampling techniques}

We determined the sample size to generate nationally and divisionally representative estimates for the selected indicators with prevalence ranging from $4 \%$ to $98 \%$. We used a multistage cluster sampling technique. We considered the type I error, $\alpha=0.05$; margin of error, $d=0.05$ (or $\mathrm{d}=$ prevalence $/ 2$ if prevalence is $\leq 0.1$ ); design effect, $\mathrm{DEF}=1.61$; and calculated a required sample size of 62 elderly individuals from each cluster. Accordingly, the total sample size for the elderly population was 5580 from 90 clusters in the country. Finally, we could collect data from 4894 elderly people in 82 clusters.

Different sampling techniques were applied to select the study sites in rural, urban and slum areas. In rural areas, two districts were randomly selected from each division in the first stage of four-stage sampling. From each district, two sub-districts (Upazilla) were randomly selected. In the third stage, two unions were randomly chosen from each of the selected sub-districts. The villages/mouzas/ geographically demarcated segments with 250-400 households were then identified and mapped in each union. Finally, we randomly selected two of the listed villages/ mouzas/segments from each union as study clusters.

In urban areas, to select the number of clusters from each division, we used the proportion of urban population reported in the Bangladesh Bureau of Statistics (BBS) 2011 census. ${ }^{15}$ We randomly selected 16 wards (1-4 wards/division). We then identified the Mahalla (similar to the villages) with more than 250 households, and the mahallas with $>500$ households were further subdivided into smaller geographically demarcated segments of $\sim 250$ households. We randomly picked one mahalla/segment from the listed mahalla/segments in each of the selected wards, and that was our study cluster.

In slum areas, the Census of Slum Areas and Floating Population 2014 was used for the selection of study sites. ${ }^{16}$ Slums having $\geq 300$ households were identified, and those with $>500$ households were further divided into smaller segments. Two slums/segments from the Dhaka and Chattogram divisions and one slum from each of the 


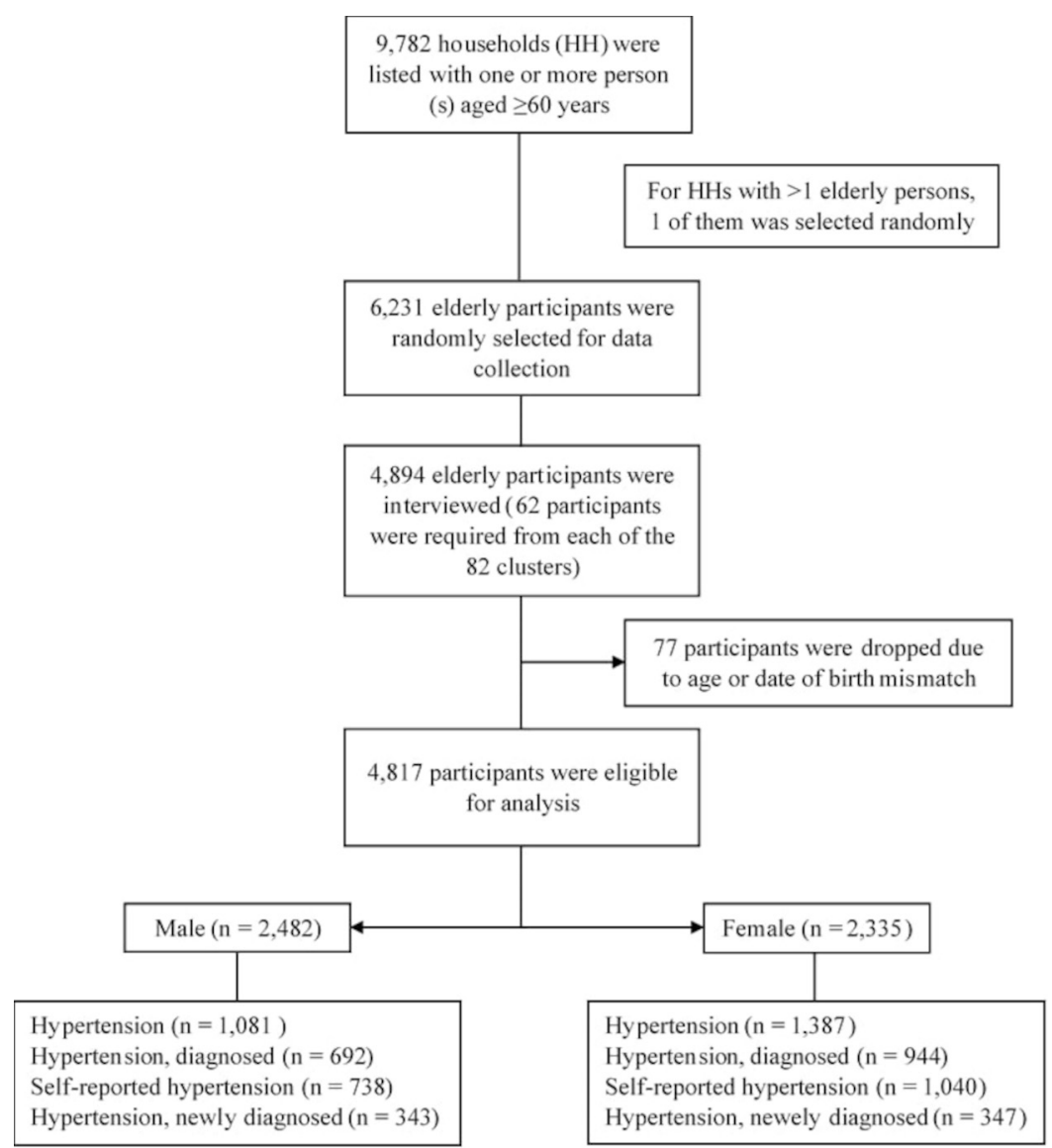

Figure 1 Study flow chart showing the process of selection of study participants.

remaining six divisions were randomly selected as study clusters.

In each cluster, data collectors first listed all households with individuals aged $\geq 60$ years. If there was any household with more than one person aged $\geq 60$ years, we randomly selected one of them. We then selected 80 elderly persons from the updated list using simple random sampling so that we could enrol 62 elderly people from a cluster. Figure 1 shows the process of selection of study participants.

\section{Data collection}

We collected data using a structured questionnaire, developed initially in English and then translated into Bengali. Data were collected using face-to-face interviews and physical measurements and were directly entered in tablet computers (Samsung Galaxy Tab A7) using a customised SurveyCTO application. ${ }^{17}$ At the end of everyday data collection, data collectors uploaded all the collected data to the server. With respect to physical measurements, we measured height (using locally made portable stadiometer), weight (using TANITA UM-070 weighing scale), waist circumference (using measuring tape) and blood pressure (using Omron HEM 7120) of the elderly people.

To collect data on self-reported hypertension, the data collector(s) asked the participant the following question, "Has a healthcare provider ever told you that you have high blood pressure, also called hypertension (other than during pregnancy)?" Before measuring blood pressure, the data collector ensured that the participant was in a resting condition for at least 15 minutes. There was a 3-minute interval between two subsequent measurements. If there was a gap of $>10 \mathrm{~mm}$ of $\mathrm{Hg}$ between the first two measurements of either SBP or DBP or both, a third measurement was taken.

Anthropometric measurements were taken based on the WHO guidelines, as specified in the Food and Nutrition Technical Assistance (FANTA) anthropometry manual. ${ }^{18}$ The weight was measured to the nearest $0.1 \mathrm{~kg}$ with light clothes, and height was measured to the nearest $0.1 \mathrm{~cm}$ in the standing position with no shoes. Waist circumference was measured to the nearest $0.1 \mathrm{~cm}$ at the end of a normal expiration, at the midpoint between the lower part of the last rib and the top of the hipbone, with the arms relaxed at the sides. Usually, we took two measurements of weight, height and waist circumference, and if the gap between the first two measurements was $>0.1 \mathrm{~kg}$ for weight and $>0.5 \mathrm{~cm}$ for height and waist circumference, we took the third measurement.

\section{Operational definitions}

The outcome variable in our analysis was hypertension status of elderly males and females. Hypertension was defined as $\mathrm{SBP} \geq 140 \mathrm{~mm} \mathrm{Hg}$ or DBP $\geq 90 \mathrm{~mm} \mathrm{Hg}$ or if the participants were told as hypertensive by any trained healthcare provider (self-reported). ${ }^{19}$ The variable was made dichotomous 
either as hypertensive (measured or self-reported) or as non-hypertensive to facilitate logistic regression.

We made a list of potential factors associated with hypertension among elderly people based on literature review and types of data collected by the survey. The socioeconomic factors were age (60-69 years vs $70+$ years), place of residence (rural, non-slum urban and slum), education (no formal education, up to primary level, 6-10 completed years and $>10$ completed years), wealth status, marital status (currently married vs others) and religion (Muslim vs others).

The behavioural factors were physical activity, fruits and vegetable consumption ( $\geq 5$ servings/day vs $<5$ servings). An elderly person was considered doing sufficient physical activity (during work, transport and recreational activities) if he or she reported at least 150 minutes of moderate-intensity physical activity per week or 75 minutes of vigorous physical activity per week or equivalent. ${ }^{20}$

Body mass index (BMI), waist circumference and selfreported diabetes were the anthropometric and clinical factors. We used the Asian cut-off to categorise BMI into underweight $\left(<18.5 \mathrm{~kg} / \mathrm{m}^{2}\right)$, normal $(\geq 18.5$ to $<23.0 \mathrm{~kg} /$ $\left.\mathrm{m}^{2}\right)$, overweight $\left(\geq 23.0\right.$ to $\left.<27.5 \mathrm{~kg} / \mathrm{m}^{2}\right)$ and obese $\left(\geq 27.5 \mathrm{~kg} / \mathrm{m}^{2}\right) .{ }^{21}$ Higher waist circumference was defined if the measurement was $\geq 90 \mathrm{~cm}$ in males and $\geq 80 \mathrm{~cm}$ in females. ${ }^{22}$ For this analysis, we considered the average of the two closest measurements for blood pressure and all anthropometric variables. Self-reported diabetes was documented if any participant reported that a trained healthcare provider ever told him or her that he or she had diabetes.

\section{Quality assurance and control}

Data collectors and the field supervisors received extensive training on interviews, anthropometric measurements and maintenance of data collection instruments. They had gone through a rigorous standardisation procedure. We field-tested the questionnaire, modified it and provided refresher training to the data collectors based on the findings of field testing. To ensure data quality, the field supervisors directly observed $5 \%$ of the interviews and reinterviewed another $5 \%$ of the randomly selected participants within 48 hours of the initial visit. Interim analyses were performed to check data quality. All the measuring tools were calibrated routinely.

\section{Statistical analysis}

We performed all the data analysis using Stata V.15.1 (Stata Corp, College Station, Texas, USA). ${ }^{23}$ All the background characteristics are reported as categorical variables. We performed principal component analysis to calculate wealth quintiles of the households of the participants. We estimated the weighted prevalence of hypertension for both elderly males and females. As the males and females differed by the distribution of risk factors and the prevalence of hypertension, we conducted separate bivariate and multivariable logistic regression to identify the factors associated with hypertension. The variables with a $p$ value $\leq 0.2$ in bivariate analysis were included in the multivariable logistic regression model. ${ }^{24}$ Variance inflation factors were also checked to assess multicollinearity among the variables. Age, BMI and waist circumference were continuous variables, and none of them was normally distributed. We converted these continuous variables into categorical variables and included them in the analysis. However, we also ran separate regression models including age, BMI and waist circumference as continuous variables and provided the results in online supplemental table 1 . We included both BMI and waist circumference separately in our initial multivariable regression analysis as both are important predictors of hypertension. In the final multivariable regression, we used only waist circumference due to its high correlation with BMI $(\mathrm{r}=0.87, \mathrm{p}<0.001)$ and its programme implications ie, waist circumference can be easily measured and interpreted for screening purpose in a low-resource setting. We also ran separate multivariable logistic regression models, including BMI as an independent variable and provided the results in online supplemental table 2. Crude and adjusted ORs were estimated at 95\% CIs and the factors with the $p$ value $<0.05$ were considered statistically significant.

\section{Ethical considerations}

The FSNSP 2018-2019 obtained the ethical approval from the Institutional Review Board (IRB) of the BRAC James P Grant School of Public Health, BRAC University, Dhaka, Bangladesh (IRB Reference number: 2018020-IR). Written informed consent was taken from the respondents before data collection and measurements.

\section{RESULTS}

Table 1 describes the characteristics of study participants. The median (IQR) age of the participants was 65.8 (62.4-71.8) years. The female participants were $48.4 \%$, and $72.0 \%$ of the study subjects were from rural areas. More females $(77.1 \%)$ reported no formal education compared to their male counterparts $(48.9 \%)$. Only one in every four females and $92 \%$ of the males were married at the time of the survey. Above one-third of the participants from both genders (42\% of males and $45 \%$ of females) reported insufficient physical activity. Nine out of ten elderly respondents consumed $<5$ servings of fruits and vegetable per day. About $37 \%$ of males and $3 \%$ of females were current smokers, whereas about $41 \%$ of elderly males and $58 \%$ of elderly females were current user of smokeless tobacco. A higher proportion (34.4\%) of females were overweight or obese than males (28.0\%). Higher waist circumference was identified among $23 \%$ of males and $41 \%$ of females. About $11 \%$ of elderly males and $13 \%$ of elderly females reported having diabetes.

Figure 2 shows the distribution of a few selected behavioural and clinical characteristics across the places of residence and genders. In our study, the prevalence of these risk factors is higher among elderly females compared to their male counterparts except for insufficient physical 
Table 1 Background characteristics of the study population by hypertension (no/yes) and gender (male/female)

\begin{tabular}{|c|c|c|c|c|c|}
\hline \multirow[b]{4}{*}{ Variables } & \multirow[b]{2}{*}{ Overall } & \multicolumn{2}{|l|}{ Hypertension } & \multicolumn{2}{|l|}{ Gender } \\
\hline & & No & Yes & Male & Female \\
\hline & $\mathrm{N}=4813$ & $\mathrm{~N}=2345$ & $\mathrm{~N}=2468$ & $\mathrm{~N}=2482$ & $\mathrm{~N}=\mathbf{2 3 3 5}$ \\
\hline & n (\%)* & n (\%)* & $\mathrm{n}(\%)^{*}$ & n (\%)* & n (\%)* \\
\hline \multicolumn{6}{|l|}{ Gender } \\
\hline Male & $2482(51.6)$ & $1401(59.7)$ & $1081(43.8)$ & - & - \\
\hline Female & $2331(48.4)$ & $944(40.3)$ & $1387(56.2)$ & - & - \\
\hline Age (years) $\dagger$ & $65.8(62.4-71.8)$ & $65.3(62.1-70.8)$ & $66.6(62.8-73.3)$ & $65.7(62.6-71.4)$ & $66.0(62.3-72.9)$ \\
\hline \multicolumn{6}{|l|}{ Age group (in years) } \\
\hline $60-69$ years & $3223(67.0)$ & $1668(71.1)$ & $1555(63.0)$ & $1725(69.5)$ & $1500(64.3)$ \\
\hline 70 years and older & $1589(33.0)$ & 677 (28.9) & $912(37.0)$ & 757 (30.5) & $834(35.7)$ \\
\hline \multicolumn{6}{|l|}{ Place of residence } \\
\hline Rural & $3463(72.0)$ & $1757(74.9)$ & $1706(69.1)$ & 1835 (73.9) & $1628(69.7)$ \\
\hline Non-slum urban & $806(16.7)$ & $292(12.5)$ & $514(20.8)$ & $394(15.9)$ & $413(17.7)$ \\
\hline Slum & $544(11.3)$ & $296(12.6)$ & $248(10.0)$ & $253(10.2)$ & $294(12.6)$ \\
\hline \multicolumn{6}{|l|}{ Educational status } \\
\hline No education & $3012(62.6)$ & $1532(65.3)$ & $1480(60.0)$ & $1214(48.9)$ & $1800(77.1)$ \\
\hline Up to 5 th grade & $556(11.6)$ & 302 (12.9) & $254(10.3)$ & $342(13.8)$ & $216(9.3)$ \\
\hline 6 th to 10 th grade & $843(17.5)$ & $376(16.0)$ & 467 (18.9) & $567(22.8)$ & $276(11.8)$ \\
\hline Above 10th grade & $402(8.4)$ & $135(5.8)$ & $267(10.8)$ & $359(14.5)$ & $43(1.8)$ \\
\hline \multicolumn{6}{|l|}{ Wealth quintile } \\
\hline Least wealthy (Q1) & $966(20.1)$ & $531(22.7)$ & 435 (17.6) & $543(21.9)$ & $423(18.1)$ \\
\hline Lower (Q2) & $968(20.1)$ & $500(21.3)$ & $468(19.0)$ & 485 (19.5) & $484(20.7)$ \\
\hline Middle (Q3) & $962(20.0)$ & 445 (19.0) & 517 (20.9) & 494 (19.9) & $469(20.1)$ \\
\hline Upper (Q4) & 957 (19.9) & 475 (20.3) & 482 (19.5) & 491 (19.8) & $467(20.0)$ \\
\hline Wealthiest (Q5) & 959 (19.9) & $393(16.8)$ & 566 (22.9) & 469 (18.9) & $491(21.0)$ \\
\hline \multicolumn{6}{|l|}{ Marital status } \\
\hline Currently married & $2860(59.4)$ & $1558(66.4)$ & $1302(52.8)$ & $2277(91.7)$ & $584(25.0)$ \\
\hline Others $\ddagger$ & $1953(40.6)$ & 787 (33.6) & $1166(47.2)$ & 205 (8.3) & $1751(75.0)$ \\
\hline \multicolumn{6}{|l|}{ Religion } \\
\hline Muslim & $4073(84.6)$ & 2005 (85.5) & 2068 (83.8) & $2113(85.1)$ & $1962(84.0)$ \\
\hline Others§ & $740(15.4)$ & $340(14.5)$ & 400 (16.2) & $369(14.9)$ & $373(16.0)$ \\
\hline \multicolumn{6}{|l|}{ Physical activity } \\
\hline$\geq 150 \mathrm{~min} /$ week & 2706 (56.2) & 1498 (63.9) & $1208(48.9)$ & $1433(57.7)$ & $1274(54.6)$ \\
\hline$<150 \mathrm{~min} /$ week & $2107(43.8)$ & 847 (36.1) & $1260(51.1)$ & 1049 (42.3) & $1061(45.4)$ \\
\hline \multicolumn{6}{|c|}{ Fruits and vegetables consumption } \\
\hline$\geq 5$ servings/day & $450(9.3)$ & $253(10.8)$ & $197(8.0)$ & 320 (12.9) & $130(5.6)$ \\
\hline$<5$ servings/day & $4363(90.7)$ & $2092(89.2)$ & $2271(92.0)$ & $2162(87.1)$ & $2205(94.4)$ \\
\hline \multicolumn{6}{|l|}{ Currently smoking } \\
\hline No & $3828(79.5)$ & $1708(72.8)$ & $2116(85.7)$ & $1564(63.0)$ & $2264(97.0)$ \\
\hline Yes & $989(20.5)$ & $637(27.2)$ & $352(14.3)$ & $918(37.0)$ & $71(3.0)$ \\
\hline \multicolumn{6}{|l|}{ Smokeless tobacco use } \\
\hline No & $2438(50.6)$ & $1146(48.9)$ & $1290(52.3)$ & $1455(58.6)$ & $983(42.1)$ \\
\hline Yes & $2379(49.4)$ & $1199(51.1)$ & $1178(47.7)$ & $1027(41.4)$ & $1352(57.9)$ \\
\hline Body mass index (BMI) $†$ & $20.9(18.6-23.8)$ & $19.9(18.0-22.3)$ & $22.1(19.6-24.9)$ & $20.7(18.6-23.5)$ & $21.2(18.7-24.3)$ \\
\hline
\end{tabular}


Table 1 Continued

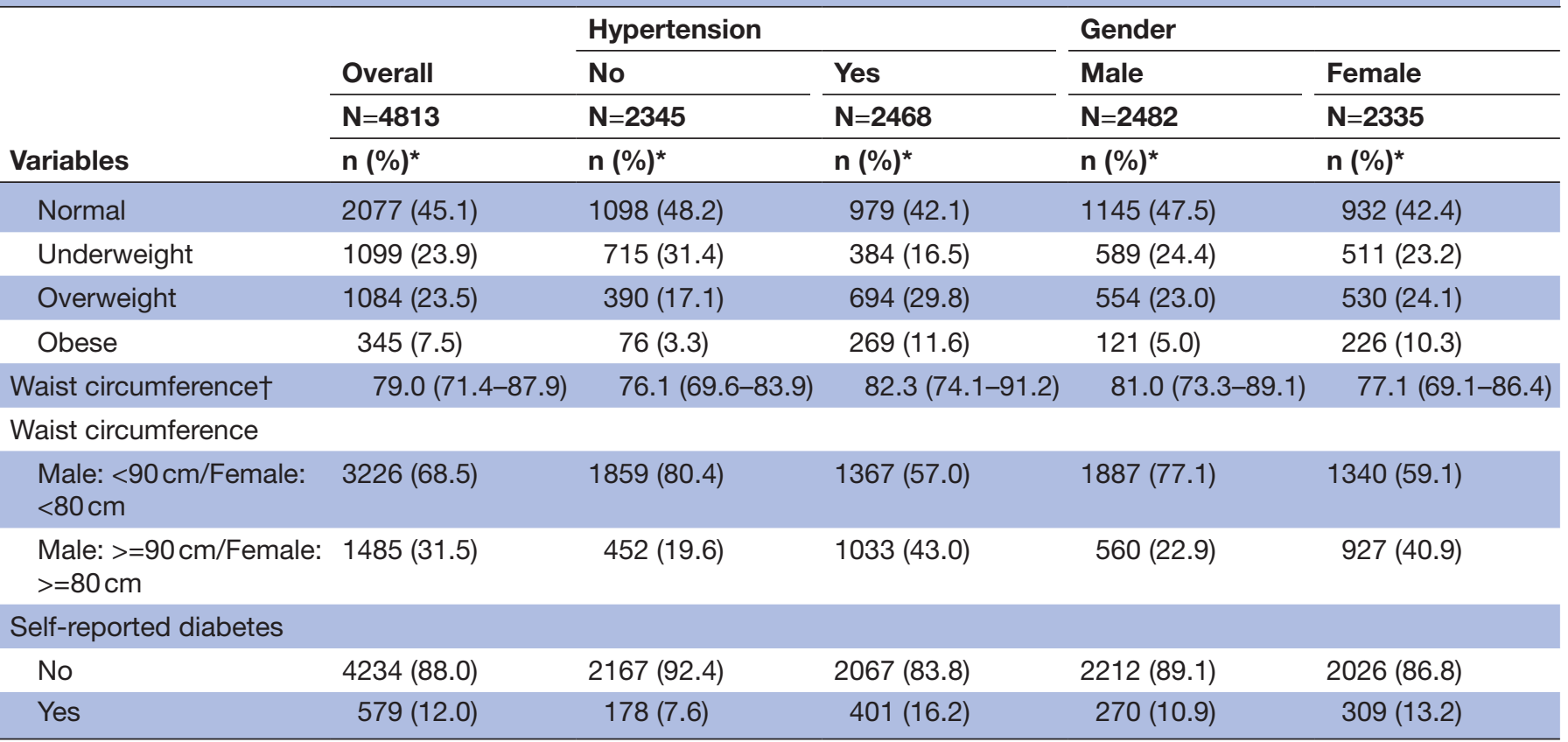

${ }^{\star}$ Column percentages.

†Median and +IQR calculated for the continuous variables.

$\ddagger$ Never married, widows, divorced and separated.

$\S$ Hindu, Christian, Buddhist and others.

activity in urban areas. Almost $80 \%$ of males and $78 \%$ of females of the non-slum urban area reported insufficient physical activity, which was around $40 \%$ in both rural and slum areas. Overall, $91 \%$ of the elderly persons were consuming $<5$ serving of fruits and vegetables per day, which was $94 \%$ in females and $87 \%$ in males. However, above $98 \%$ of slum women failed to consume the recommended servings of fruits and vegetables. The prevalence of overweight or obesity was also higher in urban females, which was about $38 \%$ compared to $22 \%$ in urban males.
Similarly, $60 \%$ of urban females were identified with higher waist circumference (abdominal obesity).

Table 2 shows prevalence of hypertension according to the characteristics of the participants and how it differs between males and females. In total, more females (56\%) were identified as hypertensive than males (42\%). Urban elderly females had the highest prevalence of hypertension $(63 \%)$, whereas the male slum dwellers had the lowest $(30 \%)$. The wealthiest of the population had the highest prevalence of hypertension in both genders $(51 \%$
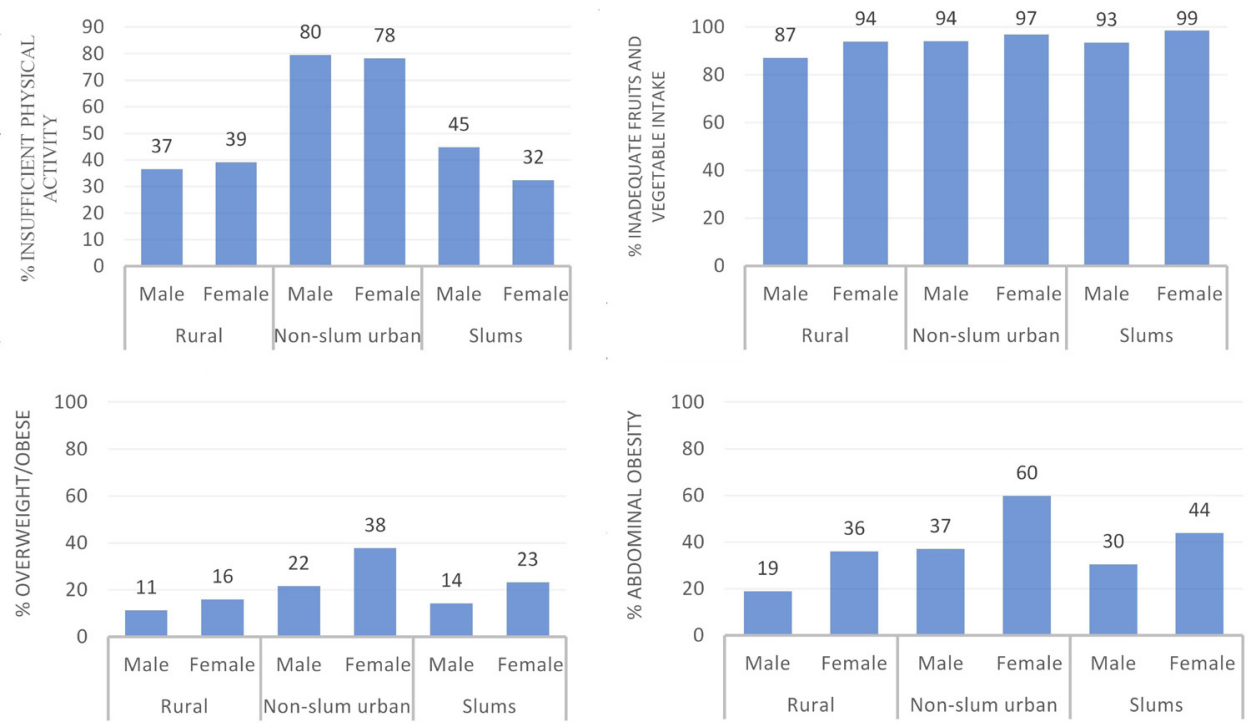

Figure 2 Selected behavioural and clinical characteristics by area of residence and gender. 
Table 2 Prevalence of hypertension according to background characteristics among elderly males and females (weighted) with $95 \% \mathrm{Cl}^{*}$

\begin{tabular}{|c|c|c|c|}
\hline & Overall & Male & Female \\
\hline Variables & $\%(95 \% \mathrm{Cl})$ & $\%(95 \% \mathrm{Cl})$ & $\%(95 \% \mathrm{Cl})$ \\
\hline Overall & 49.0 (45.2 to 52.9 ) & 42.4 (37.4 to 47.6$)$ & 56.3 (52.1 to 60.4$)$ \\
\hline \multicolumn{4}{|l|}{ Age group (in years) } \\
\hline $60-69$ years & 47.6 (43.9 to 51.4$)$ & 40.7 (35.3 to 46.3$)$ & $55.2(50.2$ to 60.0$)$ \\
\hline 70 years and older & 51.5 (45.4 to 57.6$)$ & 45.5 (37.9 to 53.3) & 58.4 (52.9 to 63.7$)$ \\
\hline \multicolumn{4}{|l|}{ Place of residence } \\
\hline Rural & 49.0 (45.0 to 52.9$)$ & 42.4 (37.3 to 47.7 ) & 56.2 (51.9 to 60.5$)$ \\
\hline Non-slum urban & 53.1 (48.4 to 57.8 & 44.9 (38.5 to 51.4$)$ & 62.9 (57.7 to 67.8$)$ \\
\hline Slum & 39.7 (32.4 to 47.4$)$ & 29.7 (24.0 to 36.1$)$ & 50.3 (40.9 to 59.6$)$ \\
\hline \multicolumn{4}{|l|}{ Educational status } \\
\hline No education & 46.9 (42.6 to 51.2$)$ & 34.4 (29.2 to 40.0$)$ & 55.6 (51.0 to 60.2$)$ \\
\hline Up to 5 th grade & 49.0 (40.3 to 57.8$)$ & 44.1 (31.8 to 57.2 ) & 57.1 (47.4 to 66.2$)$ \\
\hline 6 th to 10 th grade & 50.6 (45.0 to 56.1$)$ & 47.4 (41.0 to 53.8$)$ & 58.8 (47.3 to 69.5$)$ \\
\hline Above 10th grade & 66.8 (58.3 to 74.3$)$ & 65.7 (56.8 to 73.6 ) & 81.2 (48.5 to 95.2$)$ \\
\hline \multicolumn{4}{|l|}{ Wealth quintile } \\
\hline Least wealthy (Q1) & 44.9 (38.8 to 51.1$)$ & 39.3 (31.9 to 47.1$)$ & 52.4 (43.5 to 61.1$)$ \\
\hline Lower (Q2) & 48.4 (43.8 to 53.0$)$ & 39.0 (33.9 to 44.3$)$ & 57.5 (51.4 to 63.3$)$ \\
\hline Middle (Q3) & $51.2(45.3$ to 57.1$)$ & 45.1 (38.1 to 52.2$)$ & 58.2 (50.4 to 65.7$)$ \\
\hline Upper (Q4) & 46.4 (38.0 to 55.1$)$ & 41.2 (31.5 to 51.8$)$ & 52.2 (41.1 to 63.1$)$ \\
\hline Wealthiest (Q5) & 56.5 (51.2 to 61.7$)$ & 51.3 (44.6 to 57.8 ) & 61.7 (51.9 to 70.6$)$ \\
\hline \multicolumn{4}{|l|}{ Marital status } \\
\hline Currently married & 44.9 (40.7 to 49.2$)$ & 41.4 (36.3 to 46.8 ) & 54.0 (48.2 to 59.7$)$ \\
\hline Others $†$ & 57.8 (53.6 to 61.9$)$ & 57.8 (48.6 to 66.4 ) & 57.8 (53.2 to 62.3$)$ \\
\hline \multicolumn{4}{|l|}{ Religion } \\
\hline Muslim & 48.5 (44.0 to 53.0$)$ & 41.7 (36.0 to 47.6$)$ & 56.1 (51.3 to 60.8$)$ \\
\hline Others $\ddagger$ & 51.6 (47.4 to 55.8$)$ & 46.0 (39.0 to 53.2$)$ & 57.3 (52.5 to 62.1$)$ \\
\hline \multicolumn{4}{|l|}{ Physical activity } \\
\hline$\geq 150 \mathrm{~min} /$ week & 44.6 (40.9 to 48.3$)$ & 36.5 (31.3 to 42.0$)$ & 53.8 (49.6 to 57.9$)$ \\
\hline$<150 \mathrm{~min} /$ week & 56.2 (51.0 to 61.2$)$ & 52.3 (45.6 to 59.0 ) & 60.1 (53.9 to 66.1$)$ \\
\hline \multicolumn{4}{|c|}{ Fruits and vegetables consumption } \\
\hline$\geq 5$ servings/day & 44.7 (36.6 to 53.0$)$ & $37.0(27.4$ to 47.7$)$ & 62.6 (50.9 to 73.0$)$ \\
\hline$<5$ servings/day & 49.5 (45.5 to 53.4$)$ & $43.2(38.2$ to 48.3$)$ & $55.9(51.4$ to 60.3$)$ \\
\hline \multicolumn{4}{|l|}{ Current smokers } \\
\hline No & $52.2(48.2$ to 56.3$)$ & 46.7 (41.1 to 52.3$)$ & 56.4 (52.1 to 60.6$)$ \\
\hline Yes & $34.8(29.9$ to 40.1$)$ & $33.9(28.5$ to 39.7$)$ & $52.2(36.0$ to 68.0$)$ \\
\hline \multicolumn{4}{|l|}{ Smokeless tobacco use } \\
\hline No & 49.3 (44.7 to 53.8$)$ & 42.3 (36.9 to 47.8$)$ & 59.1 (52.3 to 65.6$)$ \\
\hline Yes & $48.8(44.5$ to 53.1$)$ & 42.5 (36.1 to 49.3$)$ & $54.3(49.7$ to 58.8$)$ \\
\hline \multicolumn{4}{|l|}{ Body mass index } \\
\hline Normal & 46.5 (42.2 to 50.8$)$ & 38.5 (33.5 to 43.9$)$ & 56.3 (50.7 to 61.8$)$ \\
\hline Underweight & 32.9 (27.3 to 39.0$)$ & 30.0 (22.3 to 39.1$)$ & 36.6 (29.9 to 43.8$)$ \\
\hline Overweight & $64.2(58.9$ to 69.1$)$ & 60.2 (54.4 to 65.7$)$ & $68.0(59.5$ to 75.4$)$ \\
\hline Obese & 74.8 (64.3 to 83.0$)$ & 72.5 (57.7 to 83.6$)$ & 76.4 (62.6 to 86.3$)$ \\
\hline Waist circumference & & & \\
\hline
\end{tabular}


Table 2 Continued

\begin{tabular}{|c|c|c|c|}
\hline & Overall & Male & Female \\
\hline Variables & $\%(95 \% \mathrm{Cl})$ & $\%(95 \% \mathrm{Cl})$ & $\%(95 \% \mathrm{Cl})$ \\
\hline Male: $<90 \mathrm{~cm} /$ Female: $<80 \mathrm{~cm}$ & 41.7 (37.3 to 46.1$)$ & 36.6 (31.4 to 42.1$)$ & 48.9 (43.4 to 54.4$)$ \\
\hline Male: $>=90 \mathrm{~cm} /$ Female: $>=80 \mathrm{~cm}$ & 67.8 (63.7 to 71.6$)$ & 65.4 (58.4 to 71.8$)$ & $69.2(63.0$ to 74.7$)$ \\
\hline \multicolumn{4}{|l|}{ Self-reported diabetes } \\
\hline No & $47.5(43.8$ to 51.1$)$ & 40.9 (36.0 to 46.0$)$ & 54.9 (51.1 to 58.7$)$ \\
\hline Yes & 64.9 (55.2 to 73.5$)$ & 60.5 (49.6 to 70.5$)$ & 68.5 (56.2 to 78.7 ) \\
\hline
\end{tabular}

${ }^{*}$ Test was done between hypertension (yes vs no) and gender (male vs female) for categories of the variables. †Never married, widows, divorced and separated. łHindu, Christian, Buddhist and others.

in males and $62 \%$ in females). Married elderly males had a lower prevalence of hypertension $(41 \%)$ compared with those who were not married during the survey $(58 \%)$. The prevalence of hypertension increased with age, education, BMI and waist circumference in both genders. However, the prevalence of hypertension was lower among those with sufficient physical activity and adequate consumption of fruits and vegetables. Moreover, the prevalence of hypertension was lower among current smokers (35\% in current smokers vs $52 \%$ in non-smokers). However, the prevalence of hypertension did not differ much between current users and non-users of smokeless tobacco.

We reported the results of bivariate and multivariable logistic regressions in table 3. In bivariate analysis, we found that all the selected variables were significantly associated with hypertension in males, whereas in females, we found that age, place of residence, education, wealth index, marital status, physical activity, BMI, waist circumference and diabetes were significantly associated with hypertension. However, in multivariable logistic regression analysis, we found that age $\geq 70$ years (Adjusted odds ratio, AOR with 95\% CI $1.32(1.09,1.60)$ for males vs $1.40(1.15,1.71)$ for females)) compared with 60-69 years; insufficient physical activity (AOR with 95\% CI $1.50(1.25,1.81)$ vs $1.38(1.15,1.67))$ compared with the recommended amount of physical activity; higher waist circumference (AOR with 95\% CI $2.76(2.22,3.43)$ vs 2.20 $(1.82,2.67))$ with reference to lower waist circumference i.e. male: $<90 \mathrm{~cm}$ and Female: $<80 \mathrm{~cm}$; and self-reported diabetes (AOR with 95\% CI $1.36(1.02,1.82)$ vs 1.82 (1.35, $2.45)$ ) compared with no self-reported diabetes were associated with increased odds of hypertension among both genders. Additionally, living in slums decreased odds of hypertension (AOR with 95\% CI $0.71(0.52,0.96)$ ) compared with rural residents, and education above 10th grade increased odds of hypertension (AOR with 95\% CI $1.83(1.38,2.44))$ compared with no formal education among males. Surprisingly, the elderly males who were reportedly smoker or smokeless tobacco user during data collection were found having decreased odds of hypertension in bivariate logistic regression. The similar effects of smoking persisted even after adjusting with potential confounders in multivariable logistic regression, where, being a current smoker was associated with decreased odds of hypertension among elderly males (AOR with $95 \%$ CI $0.74(0.61,0.89))$ compared with those who were currently non-smoker.

\section{DISCUSSION}

In our study, the overall prevalence of hypertension among the elderly people of Bangladesh was $49 \%$, which is similar to the weighted pooled prevalence of hypertension $(53 \%)$ in Bangladeshi population aged $\geq 60$ years reported in a 2020 systematic review and meta-analysis. ${ }^{25}$ The estimated prevalence is also very close to the south Asian prevalence of hypertension among elderlies aged $\geq 65$ years $(53 \%)$ but lower than the average prevalence in the low-income and middle-income countries $(66 \%)$ reported in a recent systematic review and meta-analysis. ${ }^{26}$ Moreever, the prevalence of hypertension reported by us is lower than the prevalence of hypertension in highincome countries. In a systematic analysis, Katherine $e t$ al demonstrated that, in 2010, the prevalence of hypertension in high-income countries was $60.8 \%$ (male: $55.3 \%$; female: $60.9 \%$ ) and $73.6 \%$ (male: $65.6 \%$; female: $77.5 \%$ ) in the age groups 60-69 years and 70+ years, respectively. ${ }^{27}$ However, our reported prevalence is higher than the prevalence previously reported in Bangladesh Demographic and Health Survey 2011, which was 35\% and 40\% for the age groups $60-69$ and $70+$ years, respectively. ${ }^{28}$ The increase in the prevalence of hypertension may be due to recent advancements in economy and infrastructure of the country and associated sedentary lifestyles and stress. ${ }^{29-31}$ Hypertension is the most important modifiable risk factor of cardiovascular diseases worldwide.$^{32}$ Hypertension is responsible for nearly $30 \%$ of all cardiovascular diseases, and a person with hypertension has nearly three times the likelihood of having cardiovascular incidents compared with non-hypertensive individuals. ${ }^{11}$ Accordingly, hypertension is a major risk factor for ischaemic heart diseases, heart failure, renal failure and stroke. ${ }^{33}$ As almost half of the population in the elderly age group in Bangladesh is hypertensive, Bangladesh must take immediate steps to address this problem. Policy makers need to pay special attention to design screening and intervention 
Table 3 Factors associated with hypertension among elderly Bangladeshi people stratified by gender

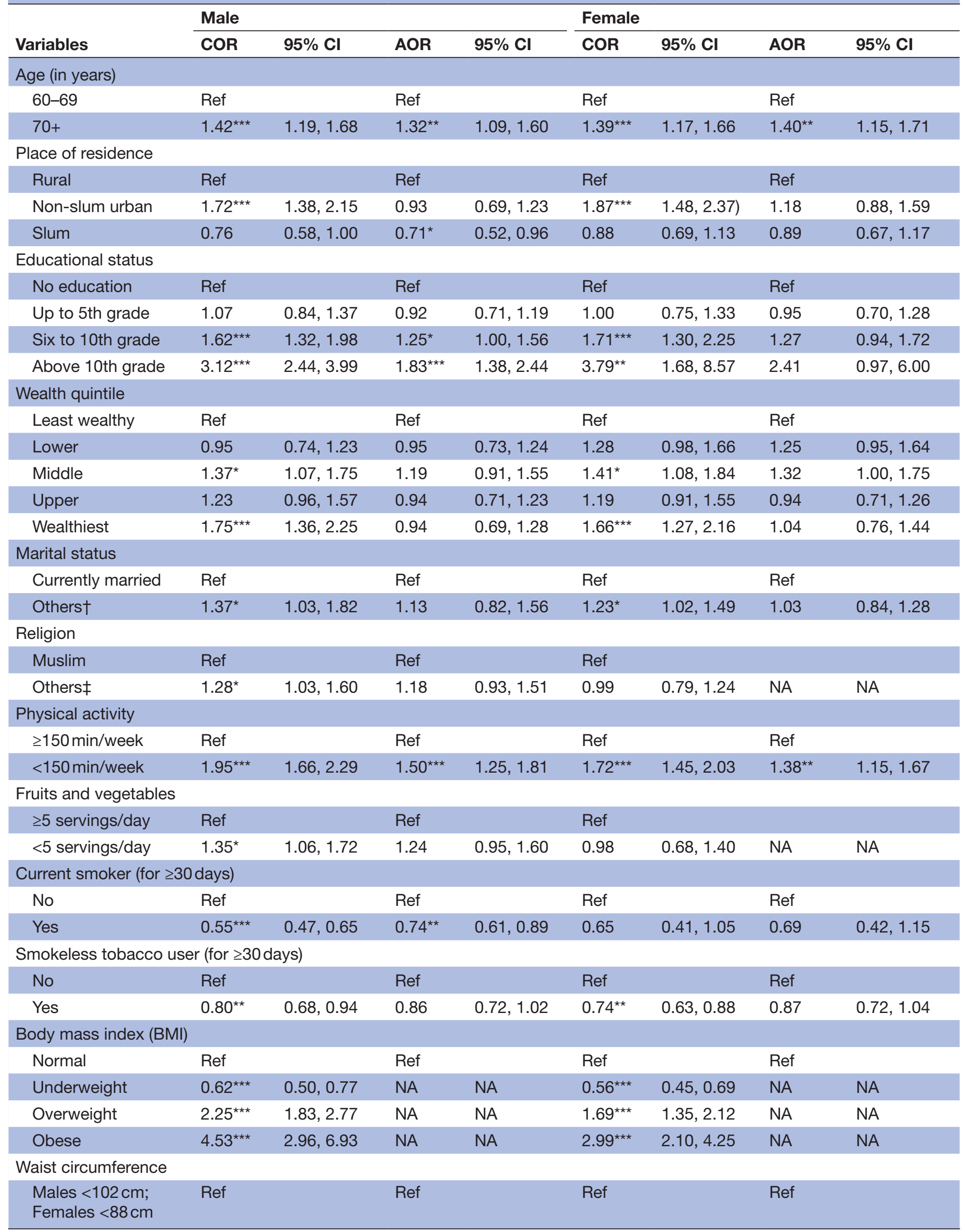


Table 3 Continued

\begin{tabular}{|c|c|c|c|c|c|c|c|c|}
\hline \multirow[b]{2}{*}{ Variables } & \multicolumn{4}{|l|}{ Male } & \multicolumn{4}{|l|}{ Female } \\
\hline & COR & $95 \% \mathrm{Cl}$ & AOR & $95 \% \mathrm{Cl}$ & COR & $95 \% \mathrm{Cl}$ & AOR & $95 \% \mathrm{Cl}$ \\
\hline $\begin{array}{l}\text { Males } \geq 102 \mathrm{~cm} ; \\
\text { Females } \geq 88 \mathrm{~cm}\end{array}$ & $3.39^{\star \star \star}$ & $2.78,4.14$ & $2.76^{\star * \star}$ & $2.22,3.43$ & $2.46^{\star \star \star}$ & $2.06,2.94$ & $2.20^{\star \star \star}$ & $1.82,2.67$ \\
\hline \multicolumn{9}{|c|}{ Self-reported diabetes } \\
\hline No & Ref & & Ref & & Ref & & Ref & \\
\hline
\end{tabular}

${ }^{*} \mathrm{p}<0.05 ;{ }^{* \star} \mathrm{p}<0.01 ;{ }^{* \star *} \mathrm{p}<0.001$.

†Never married, widows, divorced and separated.

†Hindu, Christian, Buddhist and others.

AOR, adjusted OR; COR, crude OR; NA, not applicable.

programmes for improving health and well-being of the elderly people.

After segregating by gender, the prevalence of hypertension was $42 \%$ and $56 \%$ for males and females, respectively. This higher prevalence among females is supported by several studies in Bangladesh and elsewhere. ${ }^{34}$ It may be due to a lack of ovarian hormones during the postmenopausal period. Studies suggested that ovarian hormones, especially oestrogen, may have potentials to keep blood pressure lower in premenopausal women, and lack of estrogen may be responsible for elevated blood pressure in postmenopausal women. ${ }^{35}$ Moreover, our findings indicate that women, at their advanced age, become socially more vulnerable to hypertension. For example, three out of four elderly women did not have a spouse, and it may affect their healthcare seeking and treatment. The government should pay additional attention to the vulnerability of women while designing hypertension prevention and control programmes in Bangladesh.

Our study corroborated the fact that the prevalence of hypertension increases with age in both genders. Studies conducted in Bangladesh, ${ }^{13}$ India, ${ }^{36}$ Pakistan, ${ }^{37}$ Nepal, ${ }^{38}$ Indonesia $^{39}$ and China ${ }^{40}$ have shown that the older age group had a higher prevalence of hypertension. The biological effect of the increased arterial resistance due to age-related changes in the arterial wall, that is, thickening of the arterial wall in old ages, may contribute to high risk of hypertension. ${ }^{41}$ Bangladesh is in the midst of a demographic transition, and with the decreasing trend of birth and death rate, the proportion of the elderly population is growing. This demographic transition will eventually add more hypertensive patients and create more pressure on the already overburdened health system of the country. In this study, we also found that insufficient physical activity increased the odds of hypertension in both genders. Elderlies, who reported less than 150 minutes of moderate-intensity or equivalent physical activity per week, had around 1.5 times higher odds of having hypertension compared to those with $150 \mathrm{~min}$ or more such physical activities. This finding is supported by numerous studies. ${ }^{13} 3842$ Besides, physical inactivity was also found to be associated directly with stroke and ischaemic heart diseases. ${ }^{43}$ In our study, we also found that elderly males and females with higher waist circumference had higher odds of hypertension. Several studies have reported that higher waist circumference, as it represents abdominal obesity, is a better predictor of hypertension than BMI. ${ }^{445}$

In our study, smoking use was inversely associated with hypertension for both males and females. These findings are contrary to the existing evidence that smoking causes adverse cardiovascular events and increases the risk of coronary heart diseases. ${ }^{46}$ This finding may be due to the reverse causation because the participants might have given up the habit of smoking due to known hypertension status, and we collected the data on current smoking status only. At least one study suggested that to document the proper effects of smoking on hypertension, smoking data should be collected in a life-course approach as the effects of smoking may not appear immediately after starting or quitting smoking. ${ }^{47}$ In our analysis, fruits and vegetable consumption was not found to be significantly associated with hypertension in both genders. In the case of hypertension, fruits and vegetable consumption usually helps to increase potassium intake. However, in Bangladesh, improper processing, such as washing after cutting or overcooking, may reduce the amount of potassium. ${ }^{48}{ }^{49}$ Also, not all fruits and vegetables have a high level of potassium. However, this finding should be studied further.

Among other factors, a higher level of education was responsible for the increased odds of hypertension. Elderly males and females with more than 10 years of education had about two times higher odds of having hypertension compared with those without any formal education. Al Kibria $e t a l^{13}$ found similar results analysing the data from the Bangladesh Demographic and Health Survey 2011. Education levels may elevate wealth status making people used to a sedentary lifestyle, and eventually may increase the odds of hypertension. ${ }^{50}$ However, wealth index did not show any such clear pattern, although elderlies in the upper wealth quintiles had a relatively higher prevalence of hypertension (table 2). In this study, living in slums was associated with lower odds of hypertension although the association was not statistically significant in case of the 
females. Self-reported diabetes also increased the odds of having hypertension in both males and females, and these findings are supported by several studies in Bangladesh and elsewhere. ${ }^{51-53}$

\section{Recommendations}

The factors associated with hyoertension such as insufficient physical activity and abdominal obesity are mostly modifiable by appropriate education and control programmes with support from the health and other sectors of the government. Early diagnosis of hypertension and other health problems is critical for controlling hypertension and the prevention of hypertension related complications. The gender difference in the prevalence of and factors associated with hypertension indicated that a universal prevention and control strategy might not work in this age group of population. Instead, the government should consider the gender difference and associated factors while designing hypertension screening and control programmes. Besides, education programmes should immediately be initiated to raise awareness among the elderly males and females as well as their family members on healthy lifestyles. The integration of geriatric healthcare with the general healthcare system at the primary healthcare level can be a crucial step in improving the overall health of elderly people.

\section{Strengths and limitations}

Prevalence of hypertension among elderly people was reported in several studies from Bangladesh. However, to the best of our knowledge, this is the first-ever nationally representative survey in Bangladesh investigating the prevalence and associated factors of hypertension among the elderly people. The limitations of the study include sampling challenges at the field level. The data collectors faced a relatively higher refusal in wealthier nonslum urban areas and a few isolated rural communities. Besides, seven selected rural clusters were dropped from the survey due to administrative and financial constraints, which may affect the national representativeness in the study. Among other limitations, blood pressure measurements were taken on a single day rather than longitudinal measurements on different days to confirm the diagnosis of hypertension. Also, the associations we have reported in our cross-sectional study might not be causal due to lack of temporality. Besides, we could not adjust for some strong confounders, such as salt consumption, genetic factors. ${ }^{54}$ However, these limitations emphasise the importance of further research on the determinants of hypertension among the elderly people of Bangladesh. We also recommend studying the gender difference in the context of physiology and pathophysiology of hypertension considering the effects of gonadal hormones and gender determining chromosomes on blood pressure so that management of hypertension can be customised for both males and females.

\section{CONCLUSIONS}

In our study, we found that about half of the elderly Bangladeshi people were hypertensive, and hypertension was more prevalent among elderly females in most of the sociodemographic, behavioural and clinical strata. Old age ( $\geq 70$ years), education above 10 th grade, insufficient physical activity, higher waist circumference (abdominal obesity) and self-reported diabetes were associated with hypertension in Bangladeshi elderly population. Additionally, living in slums was associated with lower odds of hypertension, and above 10th grade education was associated with higher odds of hypertension among elderly males. The government of Bangladesh should promote healthy lifestyles and emphasize early diagnosis and treatment of hypertension among the elderly population.

\section{Author affiliations}

${ }^{1}$ Centre for Non-communicable Diseases and Nutrition, BRAC James P Grant School of Public Health, BRAC University, Dhaka, Bangladesh

${ }^{2}$ National Nutrition Services (NNS), Directorate General of Health Services,

Government of Bangladesh, Dhaka, Bangladesh

${ }^{3}$ Public Health, North South University, Dhaka, Bangladesh

\section{Twitter Abu Abdullah Mohammad Hanif @aamhanif}

Acknowledgements We are thankful to all the study participants, data collectors, field supervisors and managers of the national nutrition surveillance round 2018-2019.

Contributors AAMH conceptualised and conducted the data analysis and drafted the initial manuscript. AAS, MMH, MHa, MSAK, MHo, MAU, SKS, SMMR and DM were involved in the conceptualisation and design of the study as well as reviewed and approved the final version of the manuscript. MKM led the conceptualisation/ design of the survey and supervision of data collection, critically reviewed the manuscript and approved the final version of the manuscript.

Funding The study was funded by the National Nutrition Services (NNS), Institute of Public Health Nutrition, Ministry of Health and Family Welfare, Government of Bangladesh (Memo: 45.165.032.01.00.003.2016-325; Date: 10-12-2017).

Competing interests None declared.

Patient consent for publication Not required.

Ethics approval The study obtained ethical approval from the Institutional Review Board (IRB) of the BRAC James P Grant School of Public Health, BRAC University, Dhaka, Bangladesh.

Provenance and peer review Not commissioned; externally peer reviewed.

Data availability statement Data are available upon request. The request should be sent to the IRB Chair, BRAC James P Grant School of Public Health, BRAC University, Dhaka, Bangladesh by sending an email to: irb-jpgsph@bracu.ac.bd.

Supplemental material This content has been supplied by the author(s). It has not been vetted by BMJ Publishing Group Limited (BMJ) and may not have been peer-reviewed. Any opinions or recommendations discussed are solely those of the author(s) and are not endorsed by BMJ. BMJ disclaims all liability and responsibility arising from any reliance placed on the content. Where the content includes any translated material, BMJ does not warrant the accuracy and reliability of the translations (including but not limited to local regulations, clinical guidelines, terminology, drug names and drug dosages), and is not responsible for any error and/or omissions arising from translation and adaptation or otherwise.

Open access This is an open access article distributed in accordance with the Creative Commons Attribution Non Commercial (CC BY-NC 4.0) license, which permits others to distribute, remix, adapt, build upon this work non-commercially, and license their derivative works on different terms, provided the original work is properly cited, appropriate credit is given, any changes made indicated, and the use is non-commercial. See: http://creativecommons.org/licenses/by-nc/4.0/.

ORCID iDs

Abu Abdullah Mohammad Hanif http://orcid.org/0000-0001-6274-5612 
Mehedi Hasan http://orcid.org/0000-0003-2153-4979

Malay Kanti Mridha http://orcid.org/0000-0001-9226-457X

\section{REFERENCES}

1 United Nations DoEaSA, Population Division. World population ageing, 2017 highlights (ST/ESA/SER.A/397); 2017.

2 World Health Organization. Ageing and health, 2018. Available: https://www.who.int/news-room/fact-sheets/detail/ageing-andhealth [Accessed 9 Feb 2020].

3 World Health Organization. Proposed working definition of an older person in Africa for the MDS project; 2002.

4 Rahman KMM. Unnayan Onneshan policy brief on present social context and elderly population in Bangladesh.

5 Barikdar A, Ahmed T, Lasker SP. The situation of the elderly in Bangladesh. Bangladesh J Bioethics 2016;7:27-36.

6 Jahangir AR. Bangladesh faces a challenge to ensure welfare of its aging population Inter Press Service; 2019.

7 World Health Organization. Hypertension, 2020. Available: https:// www.who.int/health-topics/hypertension/ [Accessed 9 Feb 2020].

8 World Health Organization. Q\&As on hypertension. Available: https:// www.who.int/features/qa/82/en/ [Accessed 9 Feb 2020].

9 WOrld Health Organization. Raised blood pressure: situation and trends 2020. Available: https://www.who.int/gho/ncd/risk_factors/ blood_pressure prevalence text/en/ [Accessed 10 Feb 2020].

10 World Health Organization. Global health risks: mortality and burden of disease attributable to selected major risks. Geneva, Switzerland; 2009.

11 Khanam F, Hossain MB, Mistry SK, et al. Prevalence and risk factors of cardiovascular diseases among Bangladeshi adults: findings from a cross-sectional study. J Epidemiol Glob Health 2019;9:176-84.

12 Mosley WJ, Lloyd-Jones DM. Epidemiology of hypertension in the elderly. Clin Geriatr Med 2009;25:179-89.

13 Al Kibria GM, Burrowes V, Choudhury A, et al. Sex differences in prevalence and associated factors of prehypertension and hypertension among Bangladeshi adults. Int $\mathrm{J}$ Cardiol Hypertens 2019;1:100006.

14 Khanam MA, Lindeboom W, Razzaque A, et al. Undiagnosed and uncontrolled hypertension among the adults in rural Bangladesh: findings from a community-based study. J Hypertens 2015;33:2399-406.

15 Bangladesh Bureau of Statistics (BBS). Population \& Housing Census: Preliminary Results; 2011.

16 Bangladesh Bureau of Statistics (BBS). Census of slum areas and floating population 2014; 2015.

17 Dobility Inc. surveycto. Available: https://www.surveycto.com

18 Cogill B. Anthropometric indicators measurement guide; 2003.

19 Rocella J. The seventh report of the joint National Committee on prevention, detection, evaluation, and treatment of high blood pressure. The JNC 7 report; 2003.

20 WHO. Global recommendations on physical activity for health. Available: http://www.ncbi.nlm.nih.gov/books/NBK3050572010

21 WHO Expert Consultation. Appropriate body-mass index for Asian populations and its implications for policy and intervention strategies. Lancet 2004;363:157-63.

22 Misra A, Vikram NK, Gupta R, et al. Waist circumference cutoff points and action levels for Asian Indians for identification of abdominal obesity. Int J Obes 2006;30:106-11.

23 StataCorp. Stata statistical software: release 15. College Station, TX: StataCorp LLC, 2017.

24 Maldonado G, Greenland S. Simulation study of confounderselection strategies. Am J Epidemiol 1993;138:923-36.

25 Chowdhury MZI, Rahman M, Akter T, et al. Hypertension prevalence and its trend in Bangladesh: evidence from a systematic review and meta-analysis. Clin Hypertens 2020;26:10.

26 Sarki AM, Nduka CU, Stranges S, et al. Prevalence of hypertension in low- and middle-income countries: a systematic review and metaanalysis. Medicine 2015;94:e1959.

27 Mills KT, Bundy JD, Kelly TN, et al. Global disparities of hypertension prevalence and control: a systematic analysis of population-based studies from 90 countries. Circulation 2016:134:441-50.

28 Rahman MM, Gilmour S, Akter S, et al. Prevalence and control of hypertension in Bangladesh: a multilevel analysis of a nationwide population-based survey. J Hypertens 2015;33:465-72.

29 Atkinson K, Lowe S, Moore S. Human development, occupational structure and physical inactivity among 47 low and middle income countries. Prev Med Rep 2016;3:40-5.
30 Martin SL, Kirkner GJ, Mayo K, et al. Urban, rural, and regional variations in physical activity. J Rural Health 2005;21:239-44.

31 Bishwajit Get al. Trade Liberalization, urbanization and nutrition transition in Asian countries. J Nutrit Health Food Sci 2014;2.

32 GBD 2017 Risk Factor Collaborators. Global, regional, and national comparative risk assessment of 84 behavioural, environmental and occupational, and metabolic risks or clusters of risks for 195 countries and territories, 1990-2017: a systematic analysis for the global burden of disease study 2017. Lancet 2018;392:1923-94.

33 Lionakis N, Mendrinos D, Sanidas E, et al. Hypertension in the elderly. World J Cardiol 2012;4:135-47.

34 Rahman M, Zaman MM, Islam JY, et al. Prevalence, treatment patterns, and risk factors of hypertension and pre-hypertension among Bangladeshi adults. J Hum Hypertens 2018;32:334-48.

35 Dubey RK, Oparil S, Imthurn B, et al. Sex hormones and hypertension. Cardiovasc Res 2002;53:688-708.

36 Bhise MD, Patra S. Prevalence and correlates of hypertension in Maharashtra, India: a multilevel analysis. PLoS One 2018;13:e0191948.

37 Basit A, Tanveer S, Fawwad A, et al. Prevalence and contributing risk factors for hypertension in urban and rural areas of Pakistan; a study from second national diabetes survey of Pakistan (NDSP) 2016-2017. Clin Exp Hypertens 2020;42:218-24.

38 Hasan M, Sutradhar I, Akter T, et al. Prevalence and determinants of hypertension among adult population in Nepal: data from Nepal demographic and health survey 2016. PLoS One 2018;13:e0198028.

39 Peltzer K, Pengpid S. The prevalence and social determinants of hypertension among adults in Indonesia: a cross-sectional population-based national survey. Int J Hypertens 2018;2018:1-9.

40 Song $\mathrm{H}$, Feng $\mathrm{D}$, Wang $\mathrm{R}$, et al. The urban-rural disparity in the prevalence and risk factors of hypertension among the elderly in China-a cross-sectional study. PeerJ 2019;7:e8015.

41 Shukuri A, Tewelde T, Shaweno T. Prevalence of old age hypertension and associated factors among older adults in rural Ethiopia. Integr Blood Press Control 2019;12:23-31.

42 Hypertension Study Group. Prevalence, awareness, treatment and control of hypertension among the elderly in Bangladesh and India: a multicentre study. Bull World Health Organ 2001;79:490-500.

43 Lawes CMM, Vander Hoorn S, Rodgers A, et al. Global burden of blood-pressure-related disease, 2001. Lancet 2008;371:1513-8.

44 Hirani V, Zaninotto P, Primatesta P. Generalised and abdominal obesity and risk of diabetes, hypertension and hypertension-diabetes co-morbidity in England. Public Health Nutr 2008;11:521-7.

45 Yalcin BM, Sahin EM, Yalcin E. Which anthropometric measurements is most closely related to elevated blood pressure? Fam Pract 2005;22:541-7.

46 Primatesta P, Falaschetti E, Gupta S, et al. Association between smoking and blood pressure: evidence from the health survey for England. Hypertension 2001;37:187-93.

47 Gao K, Shi X, Wang W. The life-course impact of smoking on hypertension, myocardial infarction and respiratory diseases. Sci Rep 2017;7:4330.

48 Martínez-Pineda M, Yagüe-Ruiz C, Caverni-Muñoz A, et al. Reduction of potassium content of green bean pods and chard by culinary processing. tools for chronic kidney disease. Nefrologia 2016:36:427-32.

49 Noubiap JJN, Bigna JJR, Nansseu JRN. Low sodium and high potassium intake for cardiovascular prevention: evidence revisited with emphasis on challenges in sub-Saharan Africa. J Clin Hypertens 2015;17:81-3.

50 Yabiku ST, Schlabach S. Social change and the relationships between education and employment. Popul Res Policy Rev 2009:28:533-49.

51 Chowdhury MAB, Uddin MJ, Haque MR, et al. Hypertension among adults in Bangladesh: evidence from a national cross-sectional survey. BMC Cardiovasc Disord 2016;16:22.

52 Craig LS, Gage AJ, Thomas AM. Prevalence and predictors of hypertension in Namibia: a national-level cross-sectional study. PLOS One 2018:13:e0204344.

53 Da-Mata FAF, Galvao TF, Pereira MG, et al. Prevalence of selfreported diabetes and its associated factors: a population-based study in Brazil. Int J Endocrinol 2015;2015:1-5.

54 Everett B, Zajacova A. Gender differences in hypertension and hypertension awareness among young adults. Biodemography Soc Biol 2015;61:1-17.

55 Ha SK. Dietary salt intake and hypertension. Electrolyte Blood Press 2014;12:7-18. 